\title{
Dermatomiosite e Calcinose Mamária
}

\author{
Dermatomyositis and Breast Calcinosis
}

Gil Facina, Júlio Roberto de M. Bernardes Jr.,

Afonso Celso Pinto Nazário, Cláudio Kemp,

Luiz Henrique Gebrim, Geraldo Rodrigues de Lima

\section{RESUMO}

Os autores relatam caso raro de dermatomiosite diagnosticado no Setor de Mastologia da Disciplina de Ginecologia da Universidade Federal de São Paulo - Escola Paulista de Medicina, causando deformidade mamária devido à formação de calcificações distróficas bilateralmente.

PALAVRAS-CHAVE: Doenças auto-imunes. Dermatomiosite, Mama: doença benigna. Mamografia.

\section{Introdução}

Dermatomiosite é uma doença inflamatória, degenerativa, de etiologia desconhecida, que compromete, principalmente, pele e musculatura estriada. Ocorre com maior freqüência em mulheres, na proporção $2: 1$, podendo acometer qualquer faixa etária, predominando entre os $40 \mathrm{e}$ 60 anos. Pode ocorrer na infância, quando é comum o aparecimento de calcificações distróficas ${ }^{6}$.

A dermatomiosite cursa com vasculite, a qual pode lesar os tecidos moles e favorecer o depósito de sais de cálcio. Este processo de calcificação de

Setor de Mastologia da Disciplina de Ginecologia da Universidade Federal de São Paulo - UNIFESP - Escola Paulista de Medicina

Correspondência:

Gil Facina

Rua Estado de Israel, 493 apto. 113

04022-001 - São Paulo - SP

Tel/Fax: (011) 575-7200

E-mail: facina@usa.net partes moles é denominado de calcinose ${ }^{2}$.

Durante a revisão da literatura encontramos apenas um relato de paciente com dermatomiosite e calcinose mamária ${ }^{1}$. Esta rara ocorrência associada ao dificil diagnóstico diferencial clínico com carcinoma mamário motivou nosso trabalho.

\section{Relato do caso}

VMS, 39 anos, feminina, branca, casada, natural da Bahia e residente em São Paulo há 6 anos. Apresentou menarca aos 12 anos. Antecedentes obstétricos: 10 gesta 10 para. Procurou nosso Serviço em dezembro de 1994, com queixa de nódulo mamário há 10 anos. Na inspeção mamária observamos abaulamentos e retrações bilateralmente (Figura 1). Durante a palpação evidenciamos múltiplos nódulos irregulares, mal delimitados, de consistência pétrea. A mamografia 
mostrou extensas áreas de calcificações grosseiras, irregulares, acometendo grande parte das mamas (Figura 2). Realizamos punção aspirativa por agulha fina, que foi inconclusiva devido à ausência de material

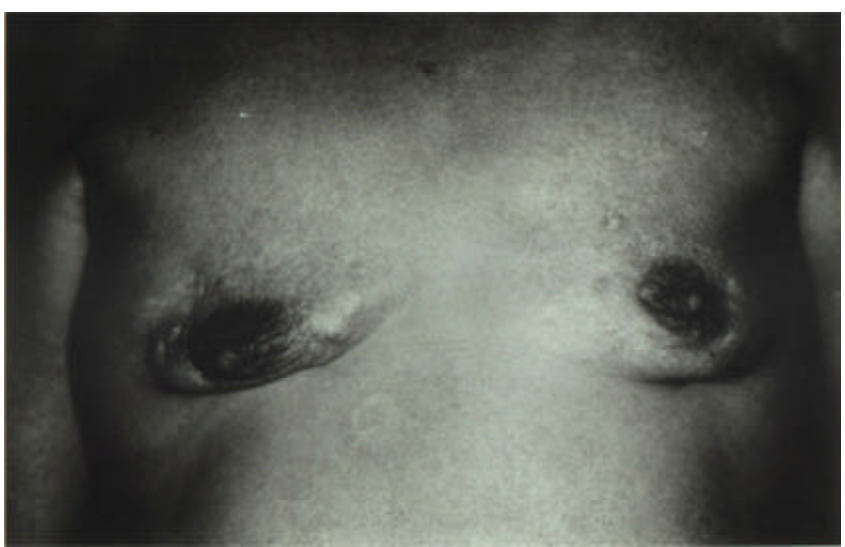

Figura 1 - Inspeção: alteração do contorno mamário em razão de abaulamentos e retrações.

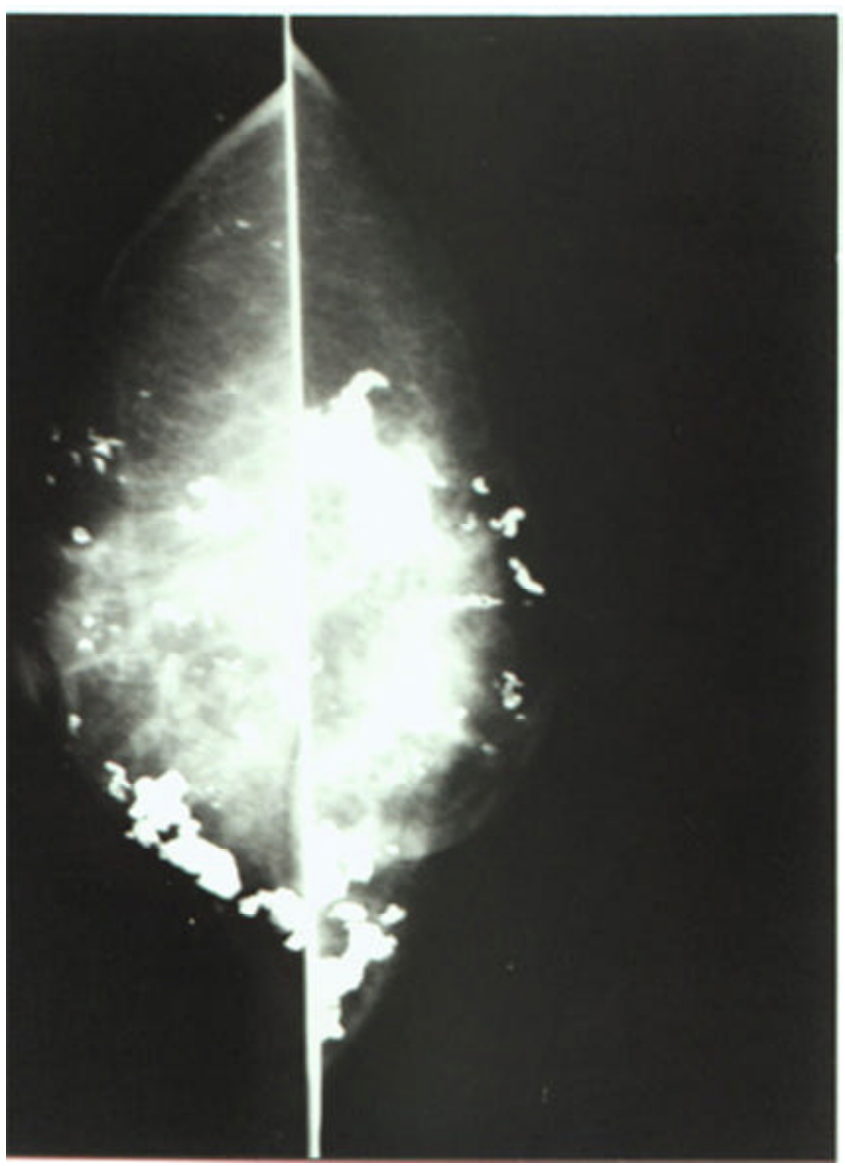

Figura 2 - Mamografia (incidência craniocaudal): presença de calcificações grosseiras distribuídas bilateralmente. celular. Indicamos a biópsia incisional com anestesia local cujo laudo concluiu tratar-se de processo inflamatório com infiltrado linfoplasmocitário, fibrose e calcificações (Figuras 3 e 4).

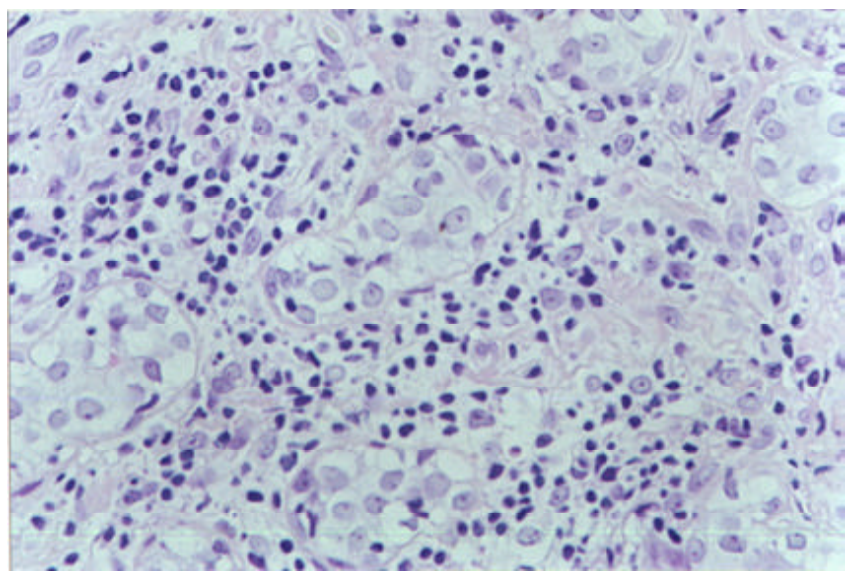

Figura 3 - Lóbulo mamário com estroma intralobular apresentando infiltrado inflamatório linfoplasmocitário (H.E., 400X).

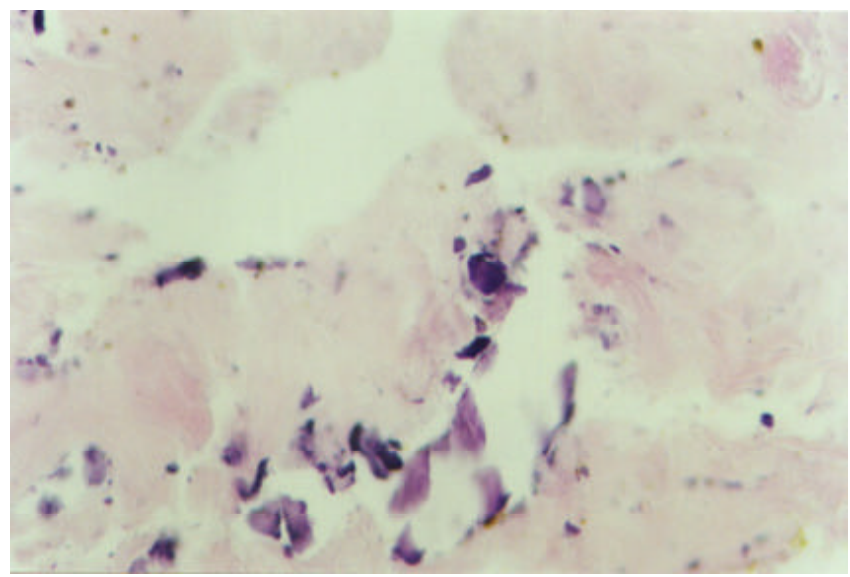

Figura 4 - Zona de estroma perilobular com hialinização de fibras colágenas e calcificações focais (H.E., 400X).

$\mathrm{Na}$ investigação complementar a paciente apresentou provas reumatológicas negativas (FAN, DNA nativo, anticorpos anti-ENA, fator reumatóide) e enzimas musculares normais (desidrogenase láctica, aldolase, creatinina fosfoquinase e transaminases). O diagnóstico foi confirmado por meio de biópsia muscular (atrofia perifascicular, necrose com macrofagia e distribuição típica das fibras musculares).

Inicialmente recebeu corticoterapia (prednisona, $40 \mathrm{mg} /$ dia) durante três meses e, por não apresentar alterações das enzimas musculares, optou-se por controle clínico. A paciente recusou intervenção cirúrgica na mama. 


\section{Discussão}

A dermatomiosite é doença de etiologia desconhecida, que produz um processo inflamatório com predomínio de infiltrado linfocitário perivascular ${ }^{5}$. Barnes e $\mathrm{Mawr}^{2}$ relatam que a incidência de malignidade em adultos é quatro a sete vezes maior que a na população geral.

Como critérios para diagnóstico da dermatomiosite é necessário que a paciente apresente pelo menos três dos parâmetros descritos a seguir:

a) fraqueza simétrica da musculatura proximal;

b) elevação das enzimas: desidrogenase láctica, transaminases, aldolase e creatina fosfoquinase;

c) miosite confirmada por biópsia muscular;

d) eletromiografia anormal;

e) aspectos dermatológicos típicos como eritema facial, edema palpebral, sinal de Gottron (pápulas violáceas, às vezes com atrofia e despigmentação, na região dorsal das articulações falangeanas) $)^{1,2}$.

No presente caso, a paciente apresentava alterações tróficas da mama sugestivas de malignidade, e ao exame mamográfico observavase bilateralmente a presença de calcificações grosseiras, bizarras e com ramificações. Por meio de radiografia simples evidenciou-se a presença de calcificações grosseiras em partes moles do antebraço (Figura 5).

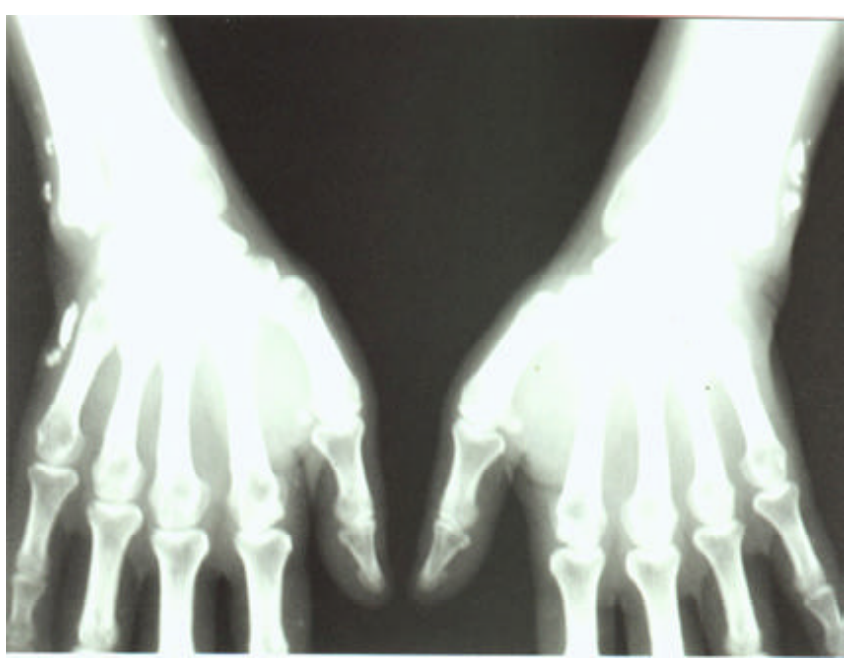

Figura 5 - Radiografia dos antebraços: presença de depósitos de cálcio em tecido mole.

O padrão da calcificação de partes moles na dermatomiosite é descrito como em forma de véu ou de papel, sempre paralelo ao eixo muscular ou ao plano interfascial ${ }^{4}$. A cintilografia é o exame mais sensivel para a detecção precoce da calcinose e para a avaliação da resposta terapêutica ${ }^{3,4}$.
Nos casos detectados em fase inicial, pequenas doses de warfarina $(1 \mathrm{mg} /$ dia) podem promover regressão da calcinose. Esta ação se deve, provavelmente, à diminuição dos níveis teciduais do ácido gama-carboxiglutâmico, aminoácido dependente de vitamina $\mathrm{K}$, e com grande potencial de ligação ao cálcio ${ }^{3}$. O diltiazem, inibidor dos canais de cálcio, é outra opção no tratamento da calcinose, pois bloquearia o fluxo de cálcio para o interior das células ${ }^{5}$.

Assim, conclui-se que dermatomiosite é causa comum de calcinose sistêmica mas, raramente, pode levar a calcificações distróficas na mama, as quais devem ser classificadas, em exame mamográfico, como lesões benignas. Dependendo do grau de deformidade mamária produzido pela doença, pode-se indicar adenomastectomia bilateral com colocação de prótese.

\section{SUMMARY}

The authors report a rare case of dermatomyositis diagnosed at the Mastology Sector of the Division of Gynecology of the Federal University of São Paulo - Escola Paulista de Medicina, which caused breast deformity due to formation of bilateral dystrophic calcifications.

KEY WORDS: Calcinosis. Dermatomyositis. Breast: benign disease. Mammography.

\section{Referências}

1. Azulay RD. Dermatologia. Rio de Janeiro: Guanabara Koogan; 1992. p. 208-21.

2. Barnes BE, Mawr B. Dermatomyositis and malignancy. A review of the literature. Ann Intern Med 1976; 84: 68-76.

3. Berger RG, Featherstone GL, Raasch RH, McCartney WH, Hadler NM. Treatment of calcinosis universalis with low-dose warfarin. Am J Med 1987; 83: 72-6.

4. Nye PJ, Perrymore WD. Mammographic appearance of calcinosis in dermatomyositis. AJR Am J Roentgenol 1995; 164: 765-6.

5. Oliveri MB, Palermo R, Mautalen C, Hübscher O. Regression of calcinosis during diltiazem treatment in juvenile dermatomyositis. J Rheumatol 1996; 23: 2152-5.

6. Sampaio SAP, Rivitti EA. Dermatologia. São Paulo: Artes Médicas; 1998. p. 361-4. 